\title{
Erratum to: ESPR uroradiology task force and ESUR paediatric working group: imaging and procedural recommendations in paediatric uroradiology, part III. Minutes of the ESPR uroradiology task force minisymposium on intravenous urography, uro-CT and MR-urography in childhood
}

\author{
Michael Riccabona • Fred E. Avni - Jean-Nicholas Dacher • Maria Beatrice Damasio • \\ Kassa Darge • M. Luisa Lobo • Lil-Sofie Ording-Müller • Frederika Papadopoulou • \\ Ulrich Willi
}

\section{Erratum to: Pediatr Radiol}

DOI 10.1007/s00247-010-1686-7

The original version of this article unfortunately contained a mistake. One of the author's surname was incorrectly captured. The correct information is given above.

The online version of the original article can be found at http://dx.doi. org/10.1007/s00247-010-1686-7.

M. Riccabona $(\square)$

K. Darge

Department of Radiology, Division of Pediatric Radiology,

Department of Radiology, Children's Hospital of Philadelphia, University Hospital Graz,

Auenbruggerplatz,

A-8036 Graz, Austria

e-mail: michael.riccabona@klinikum-graz.at

F. E. Avni

Department of Medical Imaging,

University Clinics of Brussels-Erasme Hospital,

Brussels, Belgium

Philadelphia, PA, USA

M. L. Lobo

Department of Radiology, Hospital de Santa Maria,

University Hospital,

Lisbon, Portugal

L.-S. Ording-Müller

Department of Radiology, University Hospital North Norway,

Tromsø, Norway

\section{J.-N. Dacher}

Department of Radiology, CHU de Rouen,

Rouen, France

F. Papadopoulou

Department of Radiology, Ioannina University Hospital,

Ioannina, Greece

\section{B. Damasio}

Department of Radiology, Gaslini Institute,

Genoa, Italy

U. Willi

Department of Radiology, John Hopkins University,

Baltimore, MD, USA 